\title{
Influence of definition based versus pragmatic birth registration on international comparisons of perinatal and infant mortality: population based retrospective study

\author{
(c) (1) (8) OPEN ACCESS
}

\author{
K S Joseph professor ${ }^{12}$, Shiliang Liu research scientist ${ }^{3}$, Jocelyn Rouleau data manager ${ }^{3}$, Sarka \\ Lisonkova postdoctoral fellow ${ }^{1}$, Jennifer A Hutcheon postdoctoral fellow ${ }^{1}$, Reg Sauve professor ${ }^{4}$, \\ Alexander C Allen professor ${ }^{5}$, Michael S Kramer professor ${ }^{6}$, for the Fetal and Infant Health Study \\ Group of the Canadian Perinatal Surveillance System
}

\begin{abstract}
${ }^{1}$ Department of Obstetrics and Gynaecology, University of British Columbia, Vancouver, BC, Canada V6H 3N1; ${ }^{2}$ School of Population and Public Health, University of British Columbia, Vancouver; ${ }^{3}$ Maternal and Infant Health Section, Public Health Agency of Canada, Ottawa, ON, Canada K1A OK9; ${ }^{4}$ Departments of Pediatrics and Community Health Sciences, University of Calgary, Calgary, AB, Canada T2N 2T9; ${ }^{5}$ Department of Pediatrics, Dalhousie University, Halifax, NS, Canada B3H 4N1; ${ }^{6}$ Departments of Pediatrics and of Epidemiology, Biostatistics and Occupational Health, McGill University, Montreal, QC, Canada H3H 1 P3
\end{abstract}

\begin{abstract}
Objectives To examine variations in the registration of extremely low birthweight and early gestation births and to assess their effect on perinatal and infant mortality rankings of industrialised countries.

Design Retrospective population based study.

Setting Australia, Canada, European countries, and the United States for 2004; Australia, Canada, and New Zealand for 2007.

Population National data on live births and on fetal, neonatal, and infant deaths.

Main outcome measures Reported proportions of live births with birth weight/gestational age of less than $500 \mathrm{~g}$, less than $1000 \mathrm{~g}$, less than 24 weeks, and less than 28 weeks; crude rates of fetal, neonatal, and infant mortality; mortality rates calculated after exclusion of births under $500 \mathrm{~g}$, under $1000 \mathrm{~g}$, less than 24 weeks, and less than 28 weeks.

Results The proportion of live births under $500 \mathrm{~g}$ varied widely from less than 1 per 10000 live births in Belgium and Ireland to 10.8 per 10000 live births in Canada and 16.9 in the United States. Neonatal deaths under $500 \mathrm{~g}$, as a proportion of all neonatal deaths, also ranged from less than $1 \%$ in countries such as Luxembourg and Malta to $29.6 \%$ in Canada and $31.1 \%$ in the United States. Rankings of countries based on crude fetal, neonatal, and infant mortality rates differed substantially from rankings based on rates calculated after exclusion of births with a birth weight of less than $1000 \mathrm{~g}$ or a gestational age of less than 28 weeks.
\end{abstract}

Conclusions International differences in reported rates of extremely low birthweight and very early gestation births probably reflect variations in registration of births and compromise the validity of international rankings of perinatal and infant mortality.

\section{Introduction}

Several institutions, such as the United Nations Children's Fund and the Organisation for Economic Co-operation and Development (OECD), provide international rankings of countries based on perinatal, infant, or child mortality. ${ }^{1-4}$ This annual updating of the health of children worldwide receives considerable attention in the lay press and medical journals, and frequently serves as the basis for political rhetoric, especially in industrialised countries. ${ }^{5-8}$ The subject is particularly pertinent in Canada and the United States; Canada placed 14th among about 35 OECD nations in 1960, ranked sixth in 1990, and began a steep descent to its current position of 25th place in 2008. ${ }^{2}$ The United States ranked 13th in 1960 and 22nd in 1990 and is currently in 31 st place among OECD countries. ${ }^{2}$

Although the intent of such international comparisons is to spur improvements in children's health globally, the validity of the rankings is questionable. Wide variations in birth registration procedures, even among industrialised countries, mean that comparisons of crude infant mortality may reward countries with a pragmatic approach to birth registration (that is, those 
which register only infants who survive or have a reasonable chance of survival). The medical literature documents wide variation in the registration of live births and stillbirths, especially with respect to births at the borderline of viability (for example, those with a birth weight of less than $500 \mathrm{~g}$ )..$^{9-12}$ The World Health Organization recommends that international comparisons of infant mortality should be restricted to live births with a birth weight of at least $1000 \mathrm{~g} .{ }^{13}$ The classification of deaths as neonatal deaths versus stillbirths and birth registration practices related to infants with lethal congenital anomalies (including the registration of live births that occasionally follow prenatal diagnosis and termination of pregnancy for congenital anomalies) are other potential sources of variation. ${ }^{11} 1415$

We carried out a study to assess the validity of ranking industrialised countries on the basis of perinatal and infant mortality rates. We focused on comparisons of neonatal mortality, as neonatal deaths constitute a substantial proportion of infant and child deaths and detailed information on neonatal deaths is widely available.

\section{Methods}

Our international comparisons used data for 2004, which were available from Australia, Canada, countries in Europe, and the United States. We also made comparisons using data for 2007 from Australia, Canada, and New Zealand.

Data for Canada came from the vital registration files of Statistics Canada and the hospital admission files of the Canadian Institute for Health Information. These data included information on all stillbirths, live births, neonatal deaths (0-27 days after birth), and infant deaths (0-364 days after birth) in Canada in 2004 from Statistics Canada files and all hospital live births, stillbirths, and infant deaths during the birth admission in the fiscal year 2007-8 from the discharge abstract database of the Canadian Institute for Health Information. ${ }^{15}$ For study purposes, we excluded births from the province of Ontario from Statistics Canada data because of concerns about quality, ${ }^{15}$ and hospital admission data did not include information from the province of Quebec.

Data for Australia (stillbirths in 2004 and neonatal deaths in 2007) and New Zealand (2007) came from published annual reports which provided the birth weight and gestational age of births and deaths. ${ }^{16}{ }^{17}$ Data for countries in Europe for 2004 came from the European Perinatal Health Report and other publications. ${ }^{18-20}$ The European Perinatal Health Report contained data on live births, stillbirths, neonatal deaths, and infant deaths for all European countries; in this study, we included only countries with complete birthweight specific (or gestational age specific) information on births and deaths.

Information on live births, stillbirths, neonatal deaths, and infant deaths in the United States came from the period infant mortality files of the National Center for Health Statistics for 2004. Information in these files was collated from birth and death certificates. For gestational age specific comparisons of neonatal mortality rates, we used the clinical estimate of gestation, as this is more reliable and corresponds more closely with estimates of gestational age from other countries. ${ }^{21-23}$ Stillbirths were identified in accordance with the definition of the Centers for Disease Control and Prevention (as fetal deaths with a gestational age at birth of 20 weeks or greater). ${ }^{24}$

We calculated the reported proportion of live births and the reported proportion of neonatal deaths at the lower end of the range of birth weight and gestational age in each country (that is, those with a birth weight under $500 \mathrm{~g}$ or under $1000 \mathrm{~g}$ or a gestational age of less than 24 weeks or less than 28 weeks).
We assessed the validity of using neonatal mortality rates for ranking countries' performance by examining ranks based on crude neonatal mortality rates and ranks based on neonatal mortality rates calculated after exclusion of live births with a known birth weight under $1000 \mathrm{~g}$ (or a known gestational age of less than 28 weeks). Our primary analysis focused on mortality rates calculated after exclusion of live births under $1000 \mathrm{~g}$ (rather than rates calculated after exclusion of live births at less than 28 weeks) because of international variations in the modalities used to measure gestational age (menstrual based dating, early ultrasound dating, first trimester ultrasound dating, paediatric examination, and so on).

We also assessed international variation in crude infant mortality and stillbirth rates and contrasted this with variation in infant mortality and stillbirth rates calculated after exclusion of births under $1000 \mathrm{~g}$ birth weight (or less than 28 weeks' gestation). Mortality calculations that excluded births under $1000 \mathrm{~g}$ birth weight (or less than 28 weeks' gestation) retained births with missing birth weight (or gestational age). Finally, we calculated mortality rate ratios, $95 \%$ confidence intervals, and $\mathrm{P}$ values to assess the magnitude and statistical significance of observed differences. For these comparisons, we used the United States as the reference category for neonatal mortality, Canada for infant mortality, and Australia for fetal mortality. We used EpiInfo and SAS version 9.2 for analyses.

\section{Results}

The reported proportion of live births with a birth weight of less than $500 \mathrm{~g}$ varied widely by country in 2004 . Rates were less than 1 per 10000 live births in countries such as Belgium, Ireland, Latvia, Poland, Portugal, and the Slovak Republic; 6.1 in England and Wales and Hungary; 10.8 in Canada; and 16.9 per 10000 live births in the United States (table $1 \Downarrow$ ). The proportion of live births at less than 24 weeks' gestation also varied substantially by country: 0.0 per 10000 live births in Hungary, Luxembourg, Malta, and Portugal; 7.1 in the Netherlands; 16.3 in Canada; and 26.2 per 10000 live births in the United States (web appendix table A). Neonatal deaths under $500 \mathrm{~g}$ (expressed as a proportion of all neonatal deaths) ranged from less than $1 \%$ in Luxembourg and Malta to $16.7 \%$ in Northern Ireland, 29.6\% in Canada, and 31.1\% in the United States (table $1 \Downarrow$ ). We saw similar variations in live births under $1000 \mathrm{~g}$ and less than 28 weeks and in the proportion of neonatal deaths under $1000 \mathrm{~g}$, at less than 24 weeks, and at less than 28 weeks (table $1 \Downarrow$ and web appendix table A). Figure $1 \Downarrow$ shows the relation between the reported proportion of live births under $500 \mathrm{~g}$ birth weight and crude neonatal mortality rates, and web appendix figure A shows the association between the reported proportion of live births at less than 24 weeks' gestation and crude neonatal mortality rates.

Table $2 \Downarrow$ contrasts crude neonatal mortality rates and neonatal mortality rates calculated after exclusion of live births under $1000 \mathrm{~g}$ in 25 countries in 2004 . When crude neonatal mortality rates were used for ranking, Canada was placed 18th and the United States ranked 22nd. When neonatal mortality rates were calculated after exclusion of live births under $1000 \mathrm{~g}$, Canadian and US ranks improved substantially to 12 th and 11 th place. Of the 10 countries that ranked ahead of the United States in neonatal mortality excluding live births under $1000 \mathrm{~g}$, only two countries (the Czech Republic and Germany) had rates that were significantly lower $(\mathrm{P}<0.05)$. Similarly, only one of the 11 countries that ranked ahead of Canada (the Czech Republic) had a significantly lower rate of neonatal mortality after exclusion of live births $1000 \mathrm{~g}$, and only six of the 16 countries 
that ranked ahead of England and Wales had significantly lower rates (table $2 \Downarrow$ ). Figure $2 \Downarrow$ shows the contrast in the between country pattern in crude neonatal mortality and neonatal mortality excluding live births under $1000 \mathrm{~g}$. Similar results were obtained in rankings of neonatal mortality rates calculated after exclusion of live births at less than 28 weeks' gestation (web appendix table B).

Canada ranked 12th and the United States ranked 16th in crude infant mortality rates among 18 countries, whereas the two countries ranked sixth and 12th according to infant mortality rates calculated after excluding live births under $1000 \mathrm{~g}$. Of the five countries ranking ahead of Canada according to the second index, only the Czech Republic had a significantly lower rate $(\mathrm{P}<0.05$, table $3 \Downarrow)$.

Table $4 \Downarrow$ shows crude and birthweight specific stillbirth rates in 28 countries in 2004. Comparisons based on crude stillbirth rates placed the United States in 23rd position, Canada in 27th place, and Australia last (28th). Ranks were substantially altered in comparisons of stillbirth rates calculated after excluding those with a birth weight under $1000 \mathrm{~g}$ : Australia ranked 11th, Canada ranked 12th, and the United States was placed 17th. The corrected stillbirth rate in Australia was 58\% lower than the crude rate, and only six countries had significantly lower fetal mortality rates than Australia $(\mathrm{P}<0.05)$. On the other hand, the crude stillbirth rate in Sweden declined by $5 \%$ after the correction and Sweden's rank fell from third to 10th (table $4 \Downarrow$ ).

Analyses comparing neonatal mortality rates in Australia, Canada, and New Zealand in 2007 showed similar patterns. The proportion of live births at very low birth weight or extremely preterm gestation varied significantly, and the ranks of the three countries depended on whether comparisons were made using crude neonatal mortality rates or neonatal mortality rates calculated after exclusion of very low birth weight or very early gestation live births.

\section{Discussion}

Our study shows substantial international variation in reported rates of live birth at the low end of the range of birth weight and gestational age. The proportion of neonatal deaths at these birth weights and gestational ages varied substantially as well. These differences led to substantial changes in the rankings of countries based on neonatal mortality, depending on whether the index for comparison was the crude neonatal mortality rate or a rate corrected for potential variations in birth registration at very low birth weight or very early gestation.

\section{International differences in birth registration}

The World Health Organization's International Statistical Classification of Diseases and Related Health Problems has long defined a live birth as any product of conception that shows signs of life at birth, with no consideration for birthweight or gestational age criteria. ${ }^{13}$ Although this definition remains unchallenged, countries have widely varying regulations for registration of birth that range from definition based to pragmatic. For instance, birth registration is required for all live births that satisfy the WHO's definition of live birth in Canada, England and Wales, and the United States, ${ }^{15} 25$ whereas countries such as the Czech Republic, France, and the Netherlands specify limits based on some combination of gestational age (for example, at least 22 weeks), birth weight (for example, at least $500 \mathrm{~g}$ ), or survival (for example, any live birth irrespective of birth weight that survives the first 24 hours after birth) (web appendix table C). ${ }^{18} 26$ Procedural differences due to longstanding traditions, social attitudes, and local incentives (including financial remuneration of healthcare providers) also probably dictate whether an infant at the borderline of viability is registered. Birth registration requirements for stillbirths also vary widely; countries such as the United States define stillbirths as fetal deaths delivered at or after 20 weeks' gestation, ${ }^{24}$ whereas Canada (at least 20 weeks' gestation or at least $500 \mathrm{~g}$ birth weight), ${ }^{15}$ England and Wales (at least 24 weeks' gestation), and Sweden (at least 28 weeks' gestation) have different criteria. ${ }^{18}$ Although observed differences in the proportion of live births and stillbirths at extremely low birth weight and very early gestation may reflect true between country differences, our study suggests they are more likely to be the result of the variation in birth registration practices.

\section{Implications for policy}

Our study examined the effect of variation in birth registration on international rankings of fetal, neonatal, and infant mortality. Such studies cannot provide valid international rankings of countries in terms of health or healthcare services. ${ }^{28}$ Although variation in the registration of extremely small babies and statistical variation may be corrected through appropriate analysis, other factors such as potential variation in true rates of extremely preterm birth and differences in the modality of ascertainment of gestational age cannot easily be resolved. Furthermore, any serious attempt at judging performance would have to account for potentially variable registration with regard to births affected by lethal congenital anomalies (including those born after prenatal diagnosis and termination of pregnancy $)^{11} 15$ and differential labelling of stillbirths versus live births. ${ }^{13}$ The question of prenatal diagnosis is particularly relevant, as even in countries such as Canada with a definition based birth registration system, regional variations have been noted in the registration of such births. ${ }^{15}$ At the international level, little consensus exists on whether products of pregnancy termination require birth registration, even if they meet the definition of stillbirth or live birth. In short, birth registration policies have diverse effects (including, for instance, with regard to monitoring progress towards the millennium development goals ${ }^{29}$ ), and forging a broad international consensus with regard to birth registration procedures may be worthwhile.

\section{Study limitations}

Our study has some limitations, including the use of data from national vital statistics or hospital admission databases that are not completely accurate. This problem is mitigated to some extent by our focus on birth weight (as opposed to gestational age). Other limitations of the study include use of published tabular data, which in some instances constrained the comparisons that could be made. Another limitation relates to the calculation of birthweight specific mortality rates, as some births and deaths had missing birth weights. We excluded only births and deaths with a birth weight known to be less than 1000 $\mathrm{g}$ and included births and deaths with missing birth weight in the mortality rates calculated. We chose this conservative approach to avoid "rewarding" countries with larger numbers of births with missing birth weight. Finally, our analysis involved multiple comparisons, as this is necessarily inherent in any ranking of countries. The direction of the bias introduced by multiple hypothesis testing should be noted, however. For instance, the spread of rank for the United States between crude neonatal mortality (22nd) and neonatal mortality excluding live births under $1000 \mathrm{~g}$ (only two countries had significantly lower rates) would have been even larger if we had adjusted our $\mathrm{P}$ values for multiple hypothesis testing. Similarly, adjusting for multiple hypothesis testing would have resulted in fewer than 
six countries having a significantly lower neonatal mortality rate excluding live births under $1000 \mathrm{~g}$ than England and Wales and no country having a significantly lower rate than Canada.

\section{Conclusions}

In summary, we observed large international differences in the reported proportion of live births under $500 \mathrm{~g}$ and under 1000 $\mathrm{g}$ birth weight and in neonatal deaths in these birthweight categories. International comparisons based on crude fetal, neonatal, and infant mortality rates yielded results that differed from comparisons that excluded extremely low birthweight and early gestation births, especially those at the borderline of viability. Variations in the registration of births at the borderline of viability and related problems compromise the validity of international rankings of industrialised countries by perinatal and infant mortality.

We are grateful to the vital statistics registrars of the provinces and territories and to Statistics Canada for access to the Canadian vital statistics data, the Canadian Institute for Health Information for access to the hospital admission data for Canada, and the National Center for Health Statistics for access to the perinatal mortality files of the United States. Contributing members of the Fetal and Infant Health Study Group include Sharon Bartholomew (Public Health Agency of Canada), Juan Andrés Leon (Public Health Agency of Canada), Russell Kirby (University of South Florida), and Prakesh Shah (University of Toronto).

Contributors: Questions related to international comparisons of fetal and infant mortality have been previously discussed by the Fetal and Infant Health Study Group of the Canadian Perinatal Surveillance System. KSJ proposed the study. SLiu, JR, and SLisonkova did the data analysis. KSJ drafted the manuscript. KSJ, SLiu, JR, SLisonkova, JAH, RS, ACA, and MSK reviewed the preliminary analyses and initial draft of the manuscript and provided critical comments. All the authors and the study group reviewed the final version of the manuscript. KSJ is the guarantor.

Funding: The study received no funding. KSJ's work is supported by the Child and Family Research Institute and the Peter Lougheed Research Allowance of the Canadian Institutes of Health Research (PLS56343), SLisonkova is supported by a postdoctoral fellowship award from the Michael Smith Foundation for Health Research. JAH is supported by postdoctoral fellowship awards from the Michael Smith Foundation for Health Research and the Canadian Institutes of Health Research.

Competing interests: All authors have completed the Unified Competing Interest form at www.icmje.org/coi_disclosure.pdf (available on request from the corresponding author) and declare: no financial relationships with any organisations that might have an interest in the submitted work in the previous three years; and no other relationships or activities that could appear to have influenced the submitted work.

Ethical approval: Not required, as data are publicly available.
Data sharing: No additional data available.

United Nations Children's Fund. The state of the world's children. Special ed. Unicef, 2009.

2 Organisation for Economic Co-operation and Development. OECD health data 2010: statistics and indicators. OECD, 2010.

3 Central Intelligence Agency. The world factbook 2009. CIA, 2010.

4 Inter-agency Group for Child Mortality Estimation (UNICEF, WHO, World Bank, UNPD, universities and research institutions). World development indicators. World Bank, 2010. 5 Martin S. Canada among leaders in OECD health results. CMAJ 2000;162:1032.

6 Engel M. US ranking drops in global infant mortality report. Los Angeles Times 2008 Oct 16.

7 DeNoon D. Infant mortality: US ranks 29th. WebMD Health News, 2008

8 Priest L. Canada's reputation for low infant mortality takes stunning decline: once at no 6 in world ranking, "shockingly high" death rate now puts Canada at no 24 . The Globe and Mail 2010 May 22.

9 Howell EM, Blondel B. International infant mortality rates: bias from reporting differences. Am J Public Health 1994;84:850-2.

10 Sepkowitz S. International rankings of infant mortality and the United States' vital statistics natality data collection system-failure and success. Int J Epidemiol 1995;24:583-8.

11 Sachs BP, Fretts RC, Gardner R, Hellerstein S, Wampler NS, Wise PH. The impact of extreme prematurity and congenital anomalies on the interpretation of international comparisons of infant mortality. Obstet Gynecol 1995;85:941-6.

12 Kramer MS, Platt RW, Yang H, Haglund B, Cnattingius S, Bergsjo P. Registration artifacts in international comparisons of infant mortality. Paediatr Perinat Epidemiol 2002:16:16-22.

13 World Health Organization. International statistical classification of diseases and related health problems. 10th revision. Vol 2. Instruction manual. WHO, 1993:129-34.

14 Ehrenthal DB, Wingate MS, Kirby RS. Variation by state in outcome classification for deliveries less than $500 \mathrm{~g}$ in the United States. Matern Child Health J 2011;15:42-8.

15 Public Health Agency of Canada. Canadian perinatal health report, 2008 ed. Minister of Public Works and Government Services Canada, 2008.

16 Laws P, Sullivan EA. Australia's mothers and babies 2007. AlHW National Perinatal Statistics Unit, 2009. (Perinatal statistics series no 23. Cat no PER 48.)

17 Ministry of Health. Perinatal and maternal mortality in New Zealand 2007: third report to the Minister of Health, July 2008 to June 2009. Ministry of Health, 2009.

18 Euro-Peristat Project in collaboration with SCPE, Eurocat and Euroneostat. European perinatal health report: data for 2004. Eurocat and Euroneostat, 2008

19 Confidential Enquiry into Maternal and Child Health. Perinatal mortality surveillance, 2004: England, Wales and Northern Ireland. CEMACH, 2006.

20 Confidential Enquiry into Maternal and Child Health. Perinatal mortality 2005: England, Wales and Northern Ireland. CEMACH, 2007.

21 Mustafa G, David RJ. Comparative accuracy of clinical estimate versus menstrual gestational age in computerized birth certificates. Public Health Rep 2001;116:15-21.

22 Ananth CV. Menstrual versus clinical estimate of gestational age dating in the United States: temporal trends and variability in indices of perinatal outcomes. Paediatr Perinat Epidemiol 2007;21(suppl 2):22-30.

23 Joseph KS, Huang L, Liu S, Ananth CV, Allen AC, Sauve R, et al. Reconciling the high rates of preterm and postterm birth in the United States. Obstet Gynecol 2007;109:813-22.

24 Centers for Disease Control and Prevention. Stillbirths. Department of Health and Human Services, Centers for Disease Control and Prevention, 2009.

25 Kowaleski J. State definitions and reporting requirements for live births, fetal deaths, and induced terminations of pregnancy. 1997 revision. National Center for Health Statistics, 1997.

26 Macfarlane A, Gissler M, Bolumar F, Rasmussen S. The availability of perinatal health indicators in Europe. Eur J Obstet Gynecol Reprod Biol 2003;111(suppl 1):S15-32.

27 Lack N, Zeitlin J, Krebs L, Kunzel W, Alexander S. Methodological difficulties in the comparison of indicators of perinatal health across Europe. Eur J Obstet Gynecol Reprod Biol 2003;111(suppl 1):S33-44.

28 MacDorman MF, Mathews TJ. Behind international rankings of infant mortality: how the United States compares with Europe. National Center for Health Statistics, 2009. (NCHS data brief, no 23.)

29 United Nations. The millennium development goals report 2008. United Nations, 2008.

Accepted: 25 November 2011

\section{Cite this as: BMJ 2012;344:e746}

This is an open-access article distributed under the terms of the Creative Commons Attribution Non-commercial License, which permits use, distribution, and reproduction in any medium, provided the original work is properly cited, the use is non commercial and is otherwise in compliance with the license. See: http://creativecommons.org/licenses/by$\mathrm{nc} / 2.0 /$ and http://creativecommons.org/licenses/by-nc/2.0/legalcode. 


\section{What is already known on this topic}

International rankings of countries based on perinatal, infant, or child mortality are a cause of debate and political rhetoric in industrialised countries

\section{What this study adds}

Substantial differences exist in reported rates of extremely low birth weight and very early gestation births in industrialised countries Such differences probably reflect arbitrary differences in birth registration, which compromise the validity of international rankings based on perinatal, infant, or child mortality

\section{Tables}

Table 1| Reported numbers of live births and neonatal deaths by country and rates of live birth under $500 \mathrm{~g}$, live birth under $1000 \mathrm{~g}$, neonatal death under $500 \mathrm{~g}$, neonatal death under $1000 \mathrm{~g}$, and crude neonatal mortality, 2004

\begin{tabular}{|c|c|c|c|c|c|c|c|}
\hline \multirow[b]{3}{*}{ Country } & \multicolumn{3}{|c|}{ Live births } & \multicolumn{3}{|c|}{ Neonatal deaths } & \multirow{3}{*}{$\begin{array}{l}\text { Crude neonatal death rate } \\
\text { (per } 1000 \text { live births) }\end{array}$} \\
\hline & \multirow[b]{2}{*}{ No } & \multicolumn{2}{|c|}{ Rate* } & \multirow[b]{2}{*}{ No } & \multicolumn{2}{|c|}{ Rate $^{*}$} & \\
\hline & & $<500 \mathrm{~g}($ per 10000$)$ & $<1000 \mathrm{~g}$ (per 10000$)$ & & $<500 \mathrm{~g}(\%)$ & $<1000 \mathrm{~g}(\%)$ & \\
\hline Austria & 78934 & 2.8 & 37.8 & 215 & 8.4 & 47.4 & 2.72 \\
\hline Belgium & 76872 & 0.4 & 33.2 & 197 & 1.5 & 42.3 & 2.56 \\
\hline Canada & 204521 & 10.8 & 45.2 & 767 & 29.6 & 61.9 & 3.75 \\
\hline Czech Republic & 97664 & 1.4 & 37.9 & 224 & 3.1 & 38.8 & 2.29 \\
\hline Denmark & 64521 & 2.2 & 33.1 & 230 & 11.2 & 48.5 & 3.56 \\
\hline England and Wales & 639721 & 6.1 & 49.4 & 2185 & 15.1 & 50.0 & 3.42 \\
\hline Estonia & 13990 & 2.1 & 40.1 & 59 & 5.1 & 40.7 & 4.22 \\
\hline Finland & 57569 & 3.8 & 30.4 & 141 & 13.3 & 48.9 & 2.45 \\
\hline Germany & 646599 & 4.8 & 50.1 & 1892 & 16.0 & 54.6 & 2.93 \\
\hline Hungary & 95118 & 6.1 & 61.0 & 423 & 11.2 & 56.9 & 4.45 \\
\hline Ireland & 62066 & 0.0 & 32.6 & 167 & 0.0 & 39.8 & 2.69 \\
\hline Latvia & 20355 & 0.0 & 28.5 & 116 & 0.0 & 24.1 & 5.70 \\
\hline Lithuania & 29480 & 1.0 & 28.2 & 136 & 2.2 & 37.5 & 4.61 \\
\hline Luxembourg & 5469 & 0.0 & 1.9 & 11 & 0.0 & 20.0 & 2.01 \\
\hline Malta & 3887 & 0.0 & 25.7 & 17 & 0.0 & 23.5 & 4.37 \\
\hline Netherlands & 181006 & 2.7 & 36.8 & 631 & 6.8 & 43.8 & 3.49 \\
\hline Northern Ireland & 22362 & 1.8 & 40.7 & 66 & 16.7 & 48.5 & 2.95 \\
\hline Norway & 57111 & 1.9 & 33.4 & 118 & 3.4 & 34.2 & 2.07 \\
\hline Poland & 356697 & 0.0 & 38.9 & 1731 & 0.0 & 39.9 & 4.85 \\
\hline Portugal & 109356 & 0.6 & 35.7 & 280 & 2.6 & 39.7 & 2.56 \\
\hline Scotland & 52911 & 4.2 & 39.5 & 161 & 4.7 & 46.0 & 3.04 \\
\hline Slovak Republic & 52388 & 0.8 & 32.8 & 134 & 1.5 & 36.6 & 2.56 \\
\hline Slovenia & 17846 & 3.4 & 38.1 & 47 & 10.6 & 51.1 & 2.63 \\
\hline Sweden & 100158 & 1.5 & 27.4 & 210 & 5.1 & 27.7 & 2.10 \\
\hline United States & 4118951 & 16.9 & 75.2 & 18429 & 31.1 & 64.7 & 4.47 \\
\hline
\end{tabular}

Rates of live birth $<500 \mathrm{~g}$ and live birth $<1000 \mathrm{~g}$ are expressed per 10000 live births; neonatal death $<500 \mathrm{~g}$ and neonatal death $<1000 \mathrm{~g}$ are expressed as percentage of all neonatal deaths. 
Table 2| Crude neonatal mortality rates, neonatal mortality rates excluding live births under $1000 \mathrm{~g}$ birth weight, ranks, and comparative rate ratios by country, 2004 (with United States as reference)

\begin{tabular}{|c|c|c|c|c|c|c|}
\hline \multirow[b]{2}{*}{ Country } & \multicolumn{3}{|c|}{ Crude neonatal mortality } & \multicolumn{3}{|c|}{ Neonatal mortality excluding live births $<1000 \mathrm{~g}$} \\
\hline & Rate* $^{*}$ & Rank & Country $v$ USA: rate ratio $(95 \% \mathrm{Cl})$ & Rate $^{*}$ & Rank & Country $v$ USA: rate ratio $(95 \% \mathrm{Cl})$ \\
\hline Luxembourg & 2.01 & 1 & $0.45(0.25$ to 0.81$)$ & 1.64 & 15 & 1.02 (0.53 to 1.96$)$ \\
\hline Norway & 2.07 & 2 & $0.46(0.39$ to 0.55$)$ & 1.33 & 4 & $0.83(0.66$ to 1.04$)$ \\
\hline Sweden & 2.10 & 3 & $0.47(0.41$ to 0.54$)$ & 1.56 & 9 & $0.97(0.83$ to 1.14$)$ \\
\hline Czech Republic & 2.29 & 4 & 0.51 (0.45 to 0.58$)$ & 1.12 & 1 & $0.70(0.58$ to 0.84$)$ \\
\hline Finland & 2.45 & 5 & 0.55 (0.46 to 0.65$)$ & 1.31 & 3 & 0.81 (0.65 to 1.02$)$ \\
\hline Slovak Republic & 2.56 & 6 & 0.57 (0.48 to 0.68$)$ & 1.63 & 12 & 1.01 (0.82 to 1.25$)$ \\
\hline Portugal & 2.56 & 6 & 0.57 (0.51 to 0.64$)$ & 1.58 & 10 & 0.98 (0.84 to 1.14$)$ \\
\hline Belgium & 2.56 & 6 & 0.57 (0.50 to 0.66$)$ & 1.49 & 6 & $0.92(0.77$ to 1.11$)$ \\
\hline Slovenia & 2.63 & 9 & 0.59 (0.44 to 0.78$)$ & 1.29 & 2 & 0.80 (0.53 to 1.21$)$ \\
\hline Ireland & 2.69 & 10 & $0.60(0.52$ to 0.70$)$ & 1.63 & 12 & 1.01 (0.83 to 1.23 ) \\
\hline Austria & 2.72 & 11 & $0.61(0.53$ to 0.70$)$ & 1.43 & 5 & 0.89 (0.74 to 1.07$)$ \\
\hline Germany & 2.93 & 12 & 0.65 (0.62 to 0.69$)$ & 1.49 & 6 & $0.92(0.87$ to 0.99$)$ \\
\hline Northern Ireland & 2.95 & 13 & 0.66 (0.52 to 0.84$)$ & 1.52 & 8 & 0.95 (0.68 to 1.33$)$ \\
\hline Scotland & 3.04 & 14 & 0.68 (0.58 to 0.79$)$ & 1.74 & 16 & 1.08 (0.88 to 1.33$)$ \\
\hline England and Wales & 3.42 & 15 & $0.76(0.73$ to 0.80$)$ & 1.77 & 17 & $1.10(1.03$ to 1.17$)$ \\
\hline Netherlands & 3.49 & 16 & 0.78 (0.72 to 0.84$)$ & 1.96 & 19 & $1.22(1.10$ to 1.36$)$ \\
\hline Denmark & 3.56 & 17 & 0.80 (0.70 to 0.91$)$ & 2.09 & 20 & $1.30(1.10$ to 1.54$)$ \\
\hline Canada & 3.75 & 18 & $0.84(0.78$ to 0.90$)$ & 1.63 & 12 & 1.01 (0.91 to 1.13$)$ \\
\hline Estonia & 4.22 & 19 & 0.94 (0.73 to 1.22$)$ & 2.51 & 21 & 1.56 (1.12 to 2.17$)$ \\
\hline Malta & 4.37 & 20 & 0.98 (0.61 to 1.57$)$ & 3.34 & 24 & 2.08 (1.21 to 3.58 ) \\
\hline Hungary & 4.45 & 21 & $0.99(0.90$ to 1.09$)$ & 1.95 & 18 & 1.21 (1.05 to 1.40$)$ \\
\hline United States & 4.47 & 22 & 1.00 & 1.61 & 11 & 1.00 \\
\hline Lithuania & 4.61 & 23 & 1.03 (0.87 to 1.22$)$ & 2.88 & 22 & 1.79 (1.45 to 2.22$)$ \\
\hline Poland & 4.85 & 24 & 1.08 (1.03 to 1.14$)$ & 2.93 & 23 & $1.82(1.70$ to 1.94$)$ \\
\hline Latvia & 5.70 & 25 & 1.27 (1.06 to 1.53$)$ & 4.32 & 25 & 2.68 (2.17 to 3.31$)$ \\
\hline
\end{tabular}


Table 3| Crude infant mortality rates, infant mortality rates excluding live births $<1000 \mathrm{~g}$ birth weight, ranks, and comparative rate ratios by country, 2004 (with Canada as reference)

\begin{tabular}{|c|c|c|c|c|c|c|}
\hline \multirow[b]{2}{*}{ Country } & \multicolumn{3}{|r|}{ Crude infant mortality } & \multicolumn{3}{|c|}{ Infant mortality excluding live births $<1000 \mathrm{~g}$} \\
\hline & Rate* $^{*}$ & Rank & Canada $v$ country: rate ratio $(95 \% \mathrm{Cl})$ & Rate* $^{*}$ & Rank & Canada $v$ country: rate ratio $(95 \% \mathrm{Cl})$ \\
\hline Sweden & 2.99 & 1 & 1.69 (1.49 to 1.92$)$ & 2.37 & 4 & 1.05 (0.90 to 1.22$)$ \\
\hline Norway & 3.01 & 2 & $1.68(1.43$ to1.97) & 3.01 & 3 & $1.08(0.89$ to 1.31$)$ \\
\hline Finland & 3.39 & 3 & $1.49(1.28$ to 1.74$)$ & 2.16 & 2 & $1.15(0.95$ to 1.40$)$ \\
\hline Czech Republic & 3.75 & 4 & 1.35 (1.20 to 1.52$)$ & 2.12 & 1 & 1.18 (1.00 to 1.38$)$ \\
\hline Belgium & 3.94 & 5 & $1.28(1.13$ to 1.46$)$ & 2.79 & 9 & $0.89(0.76$ to 1.05$)$ \\
\hline Northern Ireland & 4.02 & 6 & 1.26 (1.01 to 1.56$)$ & 2.60 & 7 & $0.96(0.73$ to 1.25$)$ \\
\hline Austria & 4.05 & 7 & $1.25(1.10$ to 1.41$)$ & 2.48 & 5 & 1.00 (0.85 to 1.18$)$ \\
\hline Germany & 4.14 & 8 & $1.22(1.14$ to 1.31$)$ & 2.65 & 8 & $0.94(0.85$ to 1.04$)$ \\
\hline Denmark & 4.43 & 9 & $1.14(1.00$ to 1.30$)$ & 2.88 & 10 & 0.87 (0.73 to 1.02$)$ \\
\hline Scotland & 4.93 & 10 & 1.02 (0.89 to 1.17$)$ & 3.51 & 13 & 0.71 (0.60 to 0.84$)$ \\
\hline England and Wales & 4.93 & 10 & $1.02(0.95$ to 1.10$)$ & 3.00 & 11 & 0.83 (0.75 to 0.91$)$ \\
\hline Canada & 5.05 & 12 & 1.00 & 2.49 & 6 & 1.00 \\
\hline Malta & 5.92 & 13 & 0.85 (0.57 to 1.29$)$ & 4.64 & 17 & $0.54(0.34$ to 0.86$)$ \\
\hline Estonia & 6.29 & 14 & $0.80(0.65$ to 1.00$)$ & 4.38 & 15 & $0.57(0.44$ to 0.74$)$ \\
\hline Hungary & 6.60 & 15 & 0.77 (0.69 to 0.84$)$ & 3.67 & 14 & 0.68 (0.59 to 0.78$)$ \\
\hline Poland & 6.77 & 17 & 0.75 (0.69 to 0.80$)$ & 4.60 & 16 & 0.54 (0.49 to 0.60$)$ \\
\hline United States & 6.70 & 16 & $0.75(0.71$ to 0.80$)$ & 3.50 & 12 & 0.71 (0.65 to 0.78$)$ \\
\hline Latvia & 9.38 & 18 & 0.54 (0.46 to 0.63 ) & 7.74 & 18 & 0.32 (0.27 to 0.39$)$ \\
\hline
\end{tabular}


Table 4 | Crude fetal mortality rates, fetal mortality rates excluding births $<1000 \mathrm{~g}$ birth weight, ranks, and comparative rate ratios by country, 2004 (with Australia as reference)

Crude fetal mortality

Country Rate* Rank Country $v$ Australia: rate ratio $(95 \% \mathrm{Cl})$

Slovak Republic

Sweden $\quad 3.15 \quad 3$

Spain $\quad 3.15 \quad 3$

Finland $\quad 3.29 \quad 5$

Germany $\quad 3.48 \quad 6$

\begin{tabular}{lll} 
Austria & $3.72 \quad 7$ \\
\hline
\end{tabular}

$\begin{array}{lll}\text { Portugal } & 3.84 & 8\end{array}$

\begin{tabular}{lll} 
Malta & 3.84 & 8 \\
\hline
\end{tabular}

Czech Republic $\quad 3.95 \quad 10$

$\begin{array}{lll}\text { Belgium } & 4.36 \quad 11\end{array}$

Norway $\quad 4.48 \quad 12$

Estonia $\quad 4.48 \quad 12$

Poland $\quad 4.86 \quad 14$

Hungary $\quad 4.98 \quad 15$

Denmark $5.12 \quad 16$

Lithuania $\quad 5.16 \quad 17$

Ireland $\quad 5.35 \quad 18$

Italy $\quad 5.42 \quad 19$

Slovenia $\quad 5.57 \quad 20$

England and Wales $5.73 \quad 21$

Northern Ireland $\quad 6.31 \quad 22$

United States $\quad 6.53 \quad 23$

Latvia $\quad 6.69 \quad 24$

Scotland $\quad 6.72 \quad 24$

Netherlands $\quad 6.98 \quad 26$

\begin{tabular}{lll}
\hline Canada & 7.11 & 27 \\
\hline
\end{tabular}

Australia

$7.46 \quad 28$

\section{Fetal mortality excluding births $<1000 \mathrm{~g}$}

Rate $^{\star}$ Rank Country $v$ Australia: rate ratio $(95 \% \mathrm{Cl})$

$1.63 \quad 0.52(0.42$ to 0.65$)$

$2.64 \quad 6 \quad 0.85(0.50$ to 1.44$)$

$2.99 \quad 10 \quad 0.96(0.84$ to 1.10$)$

$\begin{array}{lll}2.74 & 7 & 0.88(0.80 \text { to } 0.96)\end{array}$

$1.97 \quad 0.63(0.52$ to 0.77$)$

$2.40 \quad 4 \quad 0.77(0.71$ to 0.84$)$

$2.33 \quad 3 \quad 0.75(0.64$ to 0.88$)$

$2.89 \quad 0.93(0.82$ to 1.06$)$

$3.86 \quad 24 \quad 1.24(0.74$ to 2.06$)$

$2.56 \quad 5 \quad 0.82(0.71$ to 0.95$)$

$2.9190 .93(0.80$ to 1.08$)$

$3.76 \quad 19 \quad 1.21(1.04$ to 1.41$)$

$3.3713 \quad 1.08(0.81$ to 1.45$)$

$3.55 \quad 15 \quad 1.14(1.05$ to 1.25$)$

$3.58 \quad 16 \quad 1.15(1.01$ to 1.31$)$

$3.93 \quad 25 \quad 1.26(1.10$ to 1.45$)$

$3.83 \quad 21 \quad 1.23(1.01$ to 1.50$)$

$3.85 \quad 23 \quad 1.24(1.07$ to 1.43$)$

$4.97 \quad 28 \quad 1.60(1.48$ to 1.73$)$

$3.48 \quad 14 \quad 1.12(0.86$ to 1.45$)$

$3.84 \quad 22 \quad 1.23(1.14$ to 1.34$)$

$3.62 \quad 17 \quad 1.16(0.93$ to 1.46$)$

$3.62 \quad 17 \quad 1.16(1.08$ to 1.25$)$

$4.71 \quad 27 \quad 1.51$ (1.22 to 1.87$)$

$4.14 \quad 26 \quad 1.33(1.15$ to 1.54$)$

$3.81 \quad 20 \quad 1.23(1.11$ to 1.36$)$

$3.35 \quad 12 \quad 1.08(0.96$ to 1.21$)$

$\begin{array}{lll}3.11 & 11 & 1.00\end{array}$

*Fetal mortality rates expressed per 1000 total births. 


\section{Figures}

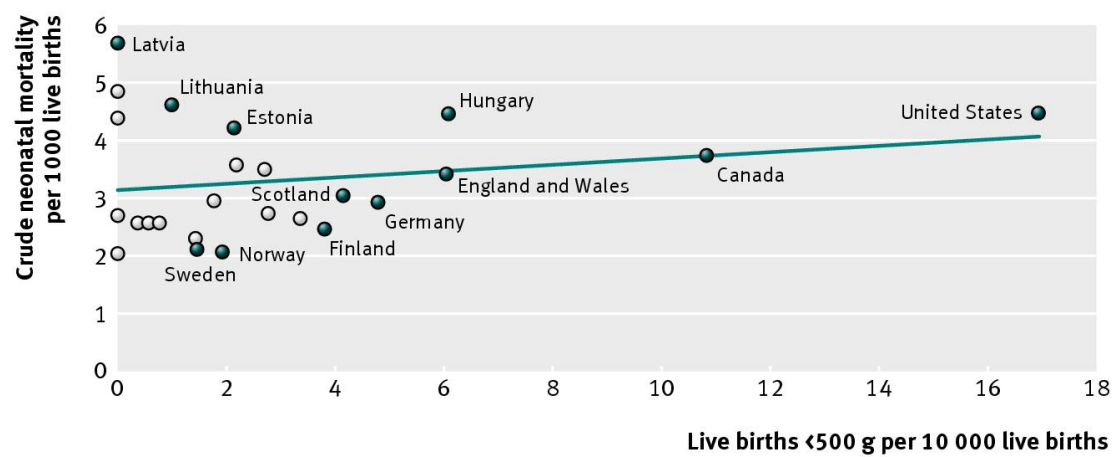

Fig 1 Association between reported proportion of live births under $500 \mathrm{~g}$ birth weight and crude neonatal mortality rates in 25 industrialised countries

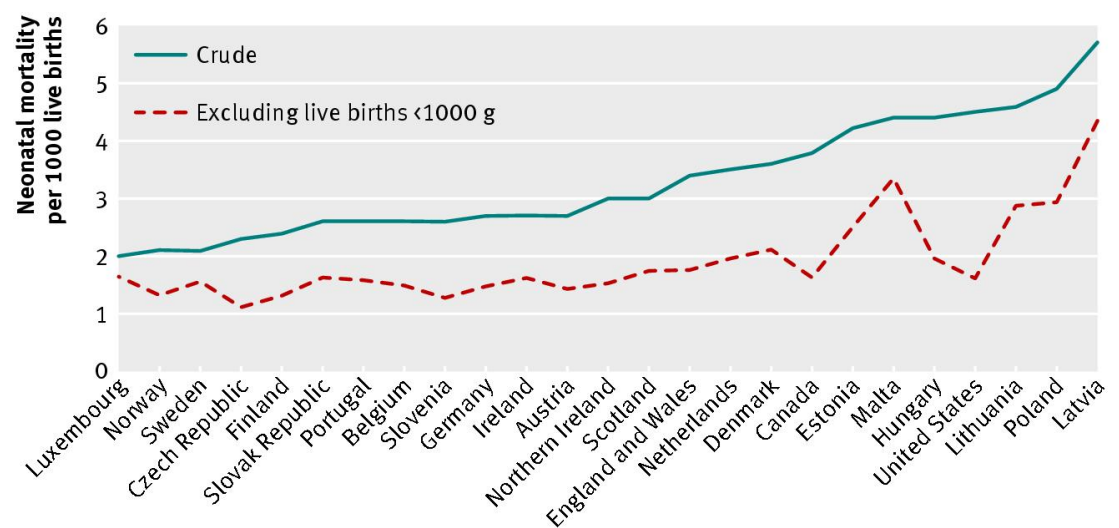

Fig 2 Differences in pattern of crude neonatal mortality rates and neonatal mortality rates excluding live births under 1000 $\mathrm{g}$ in 25 industrialised countries 